A total of 348 purebred Large White piglets were weaned at 27 days of age at a mean weight of $6.5 \mathrm{~kg}$. During the first 13 days after weaning, they were fed the same $1 \mathrm{st}$ age diet as that before weaning (T.C.P. : 21.8 p. 100 - lysine : 1.34 p. 100 - D.E. : 3418 kcal). Thereafter they received the 2 nd age diet for 28 days (T.C.P. : 22.2 p. 100, lysine : 1.16 p. 100, D.E. : $3211 \mathrm{kcal}$ ). The piglets were reared on a flat-deck (metal slatted floor). All diets were given ad libitum at the feeder. At the end of the trial the weight of the piglets ranged around $25 \mathrm{~kg}$.

Comparison of flour and pellets showed the superiority of the latter, especially as regards the feed conversion ratio. Pelleting led to a 16 p. 100 reduction of this ratio for the 1st age and 7 p. 100 for the 2 nd age.

The size of the pellets showed that :

- during the 1st age (4-6 weeks) the consumption of the small pellet $(2-5 \mathrm{~mm})$ exceeded that of the larger one. It led to a marked but non significant improvement of growth rate;

- during the 2nd age (6-10 weeks) the piglets accepted the 3 types of pellets equally, the levels of intake and growth rates being almost similar.

It may be concluded that apart the 1st age where use of small sized pellets is justified, pellets of larger size may be given to 2 nd age piglets. The advantage of the latter pellets is that their manufacturing is less expensive, their quality excellent and the level of performance obtained in the piglets identical to the former one.

\title{
Comparative utilization of bicalcic phosphate and new tricalcic phosphates by the piglet
}

\author{
P. LATIMIER *, T. LECUYER **, X. VAN ROBAIS ***, \\ J.Ph. BUFFREAU ** \\ :Etablissement départemental de l'Elevage, \\ Maison des Agriculteurs, B.P. 54, F 22190 Plerin \\ *: Laboratoire Direction des Services vétérinaires, \\ B.P. 54, F 22021 Saint-Brieuc \\ ***: Société P.C.U.K., \\ 6, place de l'Iris, Tour Manhattan, F 92087 Paris La Défense 2
}

Two trials were made to compare a control diet supplemented with bicalcic phosphate to two diets supplemented with new tricalcic phosphates. Piglets were distributed into groups at the age of 26 days at a mean weight of $7.5 \mathrm{~kg}$. At the end of the trial the weight of the piglets ranged around $30 \mathrm{~kg}$. The first trial involved 26 animals per treatment in two blocks. The second trial involved 39 animals. The diet was given in the form of flour. $\mathrm{Ca}$ and $\mathrm{P}$ contents were those recommended by Gueguen and Perez (1980).

Solubility in 2 p. 100 citric acid was about 90 p. 100 for the tricalcic phosphates according to GUEGUEN's method used for mineral complements

In the first trial growth performances were quite similar for the bicalcic diet and the two tricalcic phosphates $(534-534$ and $536 \mathrm{~g})$. The lowest feed conversion ratio was obtained with the bicalcic control $(2.07)$ but it was not significantly different from that of the tricalcic phosphates (2.19 and 2.17).

Four piglets per treatment were sacrificed for examination and determination of the bone mineralization. The calcium content of bones was for the bicalcic, the tricalcic M 19 , and the tricalcic $M 18,18.9$ p. $100,17.85$ p. 100 and 18.24 p. 100 , respectively. The phosphorus content was 8.86 p. $100,8.61$ p. 100 and 8.55 p. 100 without significant difference.

In the second trial a control bicalcic phosphate was compared to the tricalcic M 19 of the previous trial and to the new tricalcic M 19-81. Growth performances for the three 
mentioned diets were 487,503 and $505 \mathrm{~g}$, respectively without significant difference. Feed conversion ratios were $2.04,2.07$ and 2.17 . The latter value was significantly different from that of the control.

In three piglets per treatment the calcium content of bones was 19.43 p. 100 (bicalcic), 18 p. 100 (M 19), 17.87 p. 100 (M 19-81) and that of phosphorus 9.23 p. 100 (bicalcic), 8.66 p. 100 (M 19), 8.6 p. 100 (M 19-81) without significant difference.

\title{
V. - PATHOLOGY
}

\section{Evaluation of a multifactorial method for the analysis of digestive disorders at weaning}

\author{
F. MADEC * J. JOSSE *, A. CHANTAL ** \\ * Ministère de l'Agriculfure, Direction de la Oualité, Services vétérinaires, \\ Station de Pathologie porcine, F 22440 Ploufragan \\ *: Union des Coopératives agricoles de Normandie (U.C.A.N.O.R.), \\ La Folie Couvrechef, 4, rue des Roquemonts, F 14021 Caen
}

An epidemiological survey was made in Brittany (France) during the second half of 1979 in a group of 89 piggeries. A total of 515 variables was obtained in each farm and a computer processing method was used to compare the status of herds with and without weaning problems. Conditions currently associated with these disorders were selected. Ten variables proved to be prevalent and they were considered as predisposing and causative conditions for weaning diseases in the piggeries. The role of housing, feeding and management is shown: the effect of a recent episode of T.G.E. is pointed out and the multifactorial determinism of weaning disorders is discussed.

\section{Different forms of colibacillosis in the pig in France according to the Escherichia coli serological groups Comments about vaccinations}

\author{
R. RENAULT, E. LE BOURHIS, A. ALAMAGNY \\ Laboratoire vétérinaire Sanders, \\ 17, quai de l'Industrie, F 91200 Athis-Mons
}

The different forms of colibacillosis in the pig observed in France in 1980 were studied according to a serological groupage of 229 strains.

In the new-born piglet colibacillosis was induced in $27 \mathrm{p} .100$ of the cases by enteropathogenic strains (among which 40 p. 100 possessed the attachment antigen $\mathrm{K} \mathrm{88}$ ), and in 11 p. 100 of the cases by the strains responsible for the oedema disease.

In the piglet from the age of eight days and until weaning, colibacillosis was induced in 27 p. 100 of the cases by enteropathogenic strains (among which 35 p. 100 possessed the attachment antigen, $17 \mathrm{p}$. 100 were composed of the same serogroupes without attachment antigen and 48 p. 100 of «intermediate» strains), in 19 p. 100 of the cases by 